ENVIRONMENTAL EXPOSURE

\title{
Indoor exposures and respiratory symptoms in a Norwegian community sample
}

\author{
T Duelien Skorge, T M L Eagan, G E Eide, A Gulsvik, P S Bakke
}

Thorax 2005;60:937-942. doi: 10.1136/thx.2004.025973

See end of article for authors' affiliations

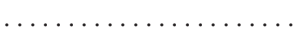

Correspondence to: Dr T Duelien Skorge, Haukeland University Hospital, N-5021 Bergen Norway; tduelien@online. no

Received 9 April 2004 Accepted 6 July 2005 Published Online First 29 July 2005
Background: Limited data are available on the effect of a poor indoor climate on the respiratory health of adults. No data are available regarding the contribution of indoor exposures to the burden of respiratory symptoms in the population.

Methods: In 1996-7 a community sample of 3181 adults aged 26-82 years was invited to participate in a survey on indoor climate and respiratory health in Hordaland County, Norway. 2401 subjects agreed to take part. Logistic regression was used to examine the relationship between eight markers of indoor exposure and physician diagnosed asthma and five respiratory symptoms, after adjustment for sex, age, smoking, educational level, smoking habits, pack years, and occupational airborne exposure.

Results: Mould exposure was associated with all the respiratory symptoms; the adjusted odds ratios (OR) varied from 1.6 (95\% confidence interval (Cl) 1.0 to 2.4 ) for cough with phlegm to $2.3(95 \% \mathrm{Cl} 1.4$ to 3.9$)$ for grade 2 dyspnoea. Keeping a cat or dog in childhood was associated with grade 2 dyspnoea and attacks of dyspnoea, with adjusted ORs of $1.3(95 \% \mathrm{Cl} 1.0$ to 1.7$)$ and $1.4(95 \% \mathrm{Cl} 1.1$ to 1.8$)$, respectively. Having a fitted carpet in the bedroom was negatively associated with three of the five respiratory symptoms. $3-5 \%$ of the frequency of the respiratory symptoms in the study population could be attributed to exposure to visible moulds.

Conclusion: Mould exposure is an independent risk factor for several respiratory symptoms in a general population covering a wide age span, but it makes only a small contribution to the respiratory symptom burden in the population at large.
1 the western world most people spend a significant amount of time indoors. ${ }^{1}$ At the same time there has been an increased awareness regarding the possible health effects of poor indoor climate. Building dampness and pet allergens are among the most commonly examined indoor risk factors for airway disease. Many of the studies examining these risk factors have focused on children..$^{2-5}$ of the studies examining the relationship between indoor pollutants and indices of airway obstruction in adults, ${ }^{6-11}$ two have included subjects aged over 50 years. ${ }^{6} 7$ Poor socioeconomic status may confound the relationship between indoor climate and respiratory disease, as socioeconomic status is associated with both the exposure ${ }^{12}{ }^{13}$ and the outcome variable. ${ }^{14}$ Only two of the studies cited have adjusted for socioeconomic status. ${ }^{68}$ Furthermore, no study has taken occupational airborne exposure into account.

Most of the studies on indoor environment in adults have focused on asthma related symptoms like wheezing and attacks of dyspnoea. The present study expands on that by including symptoms indicative of COPD such as cough with phlegm, chronic cough, and dyspnoea on exertion.

From a health planner's perspective, it is valuable to know the proportion of a disease that might be attributed to a specific exposure. To our knowledge, no community study has examined the population attributable risk of an indoor air pollutant on respiratory disease.

The objective of this community study, covering a wide age span, was to examine the relationship between self-reported indicators of a poor indoor climate and respiratory symptoms, adjusted for socioeconomic status. We also wanted to assess how this relationship varied with sex, age, smoking, and occupational airborne exposure, and the proportion of the respiratory symptom burden in the community that can be attributed to indoor air pollutants.

\section{METHODS}

\section{Study population}

The study sample was part of the second phase participants in the Hordaland County Cohort Study, which is a randomly sampled general population study on respiratory health in Western Norway. The first phase was conducted in 1985 with 3786 responders, ${ }^{15}$ and the second phase was conducted between September 1996 and May 1997. ${ }^{16}$

In the first phase 3370 subjects from the randomly selected sample participated. Before the second phase 189 had died, leaving 3181 subjects eligible for follow up. In 1996/7 these subjects, of age range $26-81$ years, received a letter explaining the survey together with a mailed questionnaire, a paid reply envelope, and an invitation to participate in an examination at the Department of Thoracic Medicine, Haukeland University Hospital. The sampling procedure and data collection in both 1985 and 1996/7 have been described previously in detail. ${ }^{15}{ }^{16}$ After a maximum of two mailed reminder letters and one telephone reminder, 2819 $(88.6 \%)$ subjects had returned the questionnaire and 2401 $(74.5 \%)$ attended for the examination.

\section{Questionnaires}

While attending the examination the subjects were also asked to complete a questionnaire with 20 questions regarding their housing and indoor climate. The analyses in this paper are based on the exposures reported while at the examination and the outcomes reported in the mailed questionnaire. The questionnaire on indoor climate has the same questions as the questionnaire used in the European Community Respiratory Health Survey. ${ }^{17}$ The questions on respiratory symptoms and asthma have previously been validated against lung function and bronchial reactivity ${ }^{18}$ and compared with the British Medical Research Council 
questionnaire on chronic bronchitis. ${ }^{19}$ The exact wording of the questions regarding indoor climate, respiratory symptoms, and asthma is given in Appendix 1.

\section{Statistical analysis}

$\chi^{2}$ tests were used to compare the prevalence of exposures between women and men, as well as comparing the prevalence of symptoms and asthma among those exposed and unexposed. Logistic regression analysis was used to estimate the odds ratios for the five respiratory symptoms and physician diagnosed asthma, adjusting for age, sex, educational level, smoking habits, pack years, occupational airborne exposure, and all the other indoor exposure variables in all models except for mould and water damage. Because of co-linearity between exposure to moulds and water damage, the odds ratio for the effect of moulds was calculated without water damage in the model and vice versa.

Smoking habits were categorised as never, ex, or current smoking. Pack years were defined as the number of cigarettes smoked per day divided by 20 multiplied by numbers of years smoked. Socioeconomic status was assessed in terms of educational level which was classified into three categories: primary, secondary, or university, based on the highest level of education obtained. ${ }^{14}$ Occupational airborne exposure was defined as self-reported exposure to dust or fumes in the workplace. ${ }^{20}$

We applied the method of fractional polynomials to decide whether to model age as a categorical or continuous variable. $^{21}{ }^{22}$ As the assumption of linearity of the logit did not hold for age as a continuous variable in the modelling of some of the outcomes, age was treated as a categorical variable with three categories.

All first order interactions between significant indoor climate exposure variables and the confounders age, sex, smoking, or educational level were investigated for each model.

For the interaction analyses, a significance level of 0.01 was used.

The adjusted attributable fractions of the indoor exposure variables moulds and cat and dog in childhood on the five respiratory symptoms and asthma were calculated.

The statistical analyses were performed using SPSS version 11.5 and Stata 8.0.

\section{RESULTS}

The distribution of smoking status and educational level for different age groups and for men and women, and the prevalence of the indoor exposure variables are given in table 1. Significantly more men than women reported having had a workplace with much dust or gas in the air, and significantly more women than men reported having kept a cat in childhood. Keeping a dog in childhood occurred more often in the youngest age group (41\%) than in the oldest age group (37\%), and more often by current smokers (43\%) than by never smokers $(34 \%)$.

The frequency of reporting mould exposure and water damage decreased with increasing age, being four times as common in the youngest as in the oldest age group. Mould exposure was related to increasing educational level, the exposure being reported three times more often in those with university education than in those with primary education.

Fitted carpets in the bedroom and in the living room were reported more often by the oldest age group than by the youngest age group, by current $(40 \%)$ than never smokers $(34 \%)$, and by those with secondary education $(40 \%)$ than by those with university education (33\%). The other relationships between the exposures and demographic variables did not reach statistical significance.
Table 2 shows the prevalence of the five respiratory symptoms and asthma in relation to the eight indoor exposure variables. There was a higher prevalence of all symptoms among those exposed to moulds than in those not exposed, which was statistically significant only for the symptoms cough with phlegm, attacks of dyspnoea, and wheezing. There was a lower prevalence of all symptoms in those who had fitted carpets in their bedroom compared with those who did not have. This was statistically significant for the symptoms cough with phlegm, chronic cough, and attacks of dyspnoea. Subjects reporting having a cat or a dog in childhood had a higher prevalence of all the respiratory symptoms than those who did not have cats or dogs in childhood.

The results from the multivariate analyses are shown in table 3. There was an increased risk of having any respiratory symptom in subjects with known exposure to moulds, after adjustment for age, sex, educational level, smoking habits, pack years, occupational airborne exposure, and all other indoor exposure variables. Although not reaching statistical significance, the odds ratio (OR) for having asthma was also increased in subjects reporting mould exposure.

For chronic cough, dyspnoea grade 2, and wheezing the association was only significant if the exposure had also been within the last 12 months. Having fitted carpets in the bedroom was negatively associated with cough with phlegm, chronic cough, and attacks of dyspnoea. Those who reported having a cat or dog in childhood had an increased risk of attacks of dyspnoea and dyspnoea grade 2, respectively, after adjustment for all other variables. None of the eight indoor exposure variables examined showed a significant association with physician diagnosed asthma.

Of all first order interactions tested, only the interaction between sex and having fitted carpets in the bedroom for the symptom chronic cough proved statistically significant $(p<0.01)$. A negative association between fitted carpets in the bedroom and having chronic cough was observed only in men (OR 0.4 (95\% CI 0.3 to 0.6) for men and OR 1.1 (95\% CI 0.8 to 1.6 ) for women).

The adjusted attributable fractions of previous mould exposure for the respiratory symptoms and physician diagnosed asthma ranged from $3.4 \%$ for cough with phlegm to $4.7 \%$ for wheezing (table 4 ). The adjusted attributable fractions for pet keeping in childhood are also shown in table 4. For dyspnoea grade 2, keeping a dog in childhood represented an adjusted attributable fraction of $7.4 \%$. Keeping a cat in childhood represented an adjusted attributable fraction of $15.3 \%$ for attacks of dyspnoea. The adjusted attributable fraction of smoking is shown for comparison, and varied from $1.9 \%$ for dyspnoea grade 2 to $30.1 \%$ for wheezing.

\section{DISCUSSION}

Subjects reporting moulds in their homes ever or within the previous 12 months had an increased risk for all respiratory symptoms examined after adjustment for sex, age, smoking, and educational level. Keeping a dog in childhood or adulthood was independently associated with dyspnoea grade 2 (childhood) and attacks of dyspnoea (adulthood). Neither of these associations varied with sex, age, or educational level. $3-5 \%$ of the frequency of the respiratory symptoms in the study population could be attributed to exposure to visible moulds, after adjustment for all covariables.

The strength of the current study is that it is a randomly sampled community study with a wide age span and a high response rate. The responders and non-responders did not differ significantly with respect to sex, age, and smoking 
Table 1 Distribution of background variables and indoor exposures by sex and age

\begin{tabular}{|c|c|c|c|c|c|}
\hline & \multirow[b]{2}{*}{$\begin{array}{l}\text { Women } \\
(n=1246)\end{array}$} & \multirow[b]{2}{*}{$\begin{array}{l}\text { Men } \\
(n=1155)\end{array}$} & \multicolumn{3}{|l|}{ Age groups } \\
\hline & & & $\begin{array}{l}26-40 \\
(n=1711)\end{array}$ & $\begin{array}{l}41-60 \\
(n=1832)\end{array}$ & $\begin{array}{l}61-82 \\
(n=1448)\end{array}$ \\
\hline \multicolumn{6}{|l|}{ Educational level } \\
\hline Primary & $247(20.1)$ & $197(17.3)$ & $93(12.3)$ & $124(12.5)$ & $227(36.7)^{*}$ \\
\hline Secondary & 713 (58.2) & $660(57.2)$ & $435(57.4)$ & $608(61.4)$ & $330(53.3)$ \\
\hline University & $266(21.7)$ & $284(24.9)$ & $230(30.3)$ & $258(26.1)$ & $62(10.0)$ \\
\hline \multicolumn{6}{|l|}{ Smoking status } \\
\hline Current & $389(31.2)$ & $402(34.8)^{*}$ & $326(42.9)$ & $415(41.8)$ & $188(29.7)^{*}$ \\
\hline Ex & $286(23.0)$ & $380(32.9)$ & $78(10.3)$ & $233(23.5)$ & $171(27.1)$ \\
\hline Never & $571(45.8)$ & $373(32.3)$ & $356(46.8)$ & $345(34.7)$ & $273(43.2)$ \\
\hline \multicolumn{6}{|l|}{ Occupational exposure } \\
\hline Yes & $381(30.6)$ & $714(61.8)$ & $238(31.2)$ & $305(30.6)$ & $157(24.5)^{*}$ \\
\hline \multicolumn{6}{|l|}{ Mould exposure } \\
\hline Only earlier & $65(5.2)$ & $51(4.4)^{\star}$ & $39(5.1)$ & $54(5.4)$ & $23(3.6)^{*}$ \\
\hline Earlier and last year & $54(4.3)$ & $53(4.6)$ & $55(7.2)$ & $42(4.2)$ & $10(1.6)$ \\
\hline \multicolumn{6}{|l|}{ Water damage } \\
\hline Only earlier & $94(7.5)$ & $101(8.7)$ & $71(9.3)$ & $86(8.6)$ & $38(5.9)^{*}$ \\
\hline Earlier and last year & $42(3.4)$ & $52(4.5)$ & $49(6.4)$ & $34(3.4)$ & $11(1.7)$ \\
\hline \multicolumn{6}{|l|}{ Fitted carpets } \\
\hline Bedroom & $464(37.2)$ & $436(37.7)$ & $236(30.9)$ & $419(42.0)$ & $245(38.2)^{*}$ \\
\hline Living room & $189(15.2)$ & $184(15.9)$ & $107(14.0)$ & $143(14.3)$ & $123(19.2)^{*}$ \\
\hline \multicolumn{6}{|l|}{ Cat } \\
\hline In adulthood & $222(17.8)$ & $234(20.3)$ & $162(21.2)$ & $238(23.9)$ & $56(8.7)^{*}$ \\
\hline In childhood & $688(55.2)$ & $582(50.4)$ & $405(53.1)$ & $512(51.4)$ & $353(55.1)$ \\
\hline \multicolumn{6}{|l|}{ Dog } \\
\hline In adulthood & $170(13.6)$ & $168(14.5)^{*}$ & 112 (14.7) & $183(18.4)$ & $43(6.7)^{*}$ \\
\hline In childhood & $461(37.0)$ & $437(37.8)$ & $316(41.4)$ & $345(34.6)$ & $237(37.0)^{*}$ \\
\hline
\end{tabular}

status. ${ }^{23}$ However, some methodological aspects need to be considered.

Firstly, the respiratory symptoms and the indoor climate variables were self-reported. Subjects with symptoms could over-report indoor exposure, leading to a false positive exposure-disease relationship. However, the participants completed the respiratory symptom questionnaire before learning about the indoor environment questionnaire, reducing the likelihood for this bias. Conversely, subjects with respiratory symptoms could over-report indoor pollution. However, a study by Williamson et al ${ }^{24}$ showed that occupants with and without respiratory symptoms tended to report less dampness in their homes than the dampness observed by outside inspectors.

Secondly, the cross-sectional design of the analyses cannot control for a selection bias caused by symptomatic subjects

Table 2 Prevalence of the five respiratory symptoms and physician diagnosed asthma among those exposed and not exposed to indoor variables

\begin{tabular}{|c|c|c|c|c|c|c|}
\hline & $\begin{array}{l}\text { Cough with } \\
\text { phlegm }\end{array}$ & Chronic cough & $\begin{array}{l}\text { Dyspnoea } \\
\text { grade } 2\end{array}$ & $\begin{array}{l}\text { Attacks of } \\
\text { dyspnoea }\end{array}$ & Wheezing & Asthma \\
\hline \multicolumn{7}{|l|}{ Moulds } \\
\hline Never & 23.6 & 12.3 & 16.4 & 14.7 & 22.0 & 6.1 \\
\hline Only earlier & 31.0 & 13.8 & 20.7 & 22.4 & 29.3 & 7.8 \\
\hline Earlier and last year & $31.8^{*}$ & 17.8 & 21.5 & $20.6^{*}$ & $39.3^{* *}$ & 7.5 \\
\hline \multicolumn{7}{|l|}{ Water damage } \\
\hline Never & 23.8 & 12.4 & 16.5 & 15.2 & 22.6 & 6.2 \\
\hline Only earlier & 27.2 & 14.4 & 19.0 & 15.4 & 27.2 & 6.7 \\
\hline Earlier and last year & 29.8 & 14.9 & 19.1 & 19.1 & 27.7 & 6.4 \\
\hline \multicolumn{7}{|l|}{ Fitted carpets in bedroom } \\
\hline Yes & $20.7^{\star *}$ & $10.9^{*}$ & 16.9 & 13.1 & 21.7 & 5.7 \\
\hline No & 26.4 & 13.7 & 16.8 & $16.7^{*}$ & 24.1 & 6.5 \\
\hline \multicolumn{7}{|c|}{ Fitted carpets in living room } \\
\hline Yes & 22.3 & 12.1 & 19.8 & 13.4 & 19.8 & 4.3 \\
\hline No & 24.7 & 12.7 & 16.3 & 15.7 & 23.8 & 6.6 \\
\hline \multicolumn{7}{|l|}{ Cat in adulthood } \\
\hline Yes & 25.7 & 12.9 & 15.6 & 14.7 & 24.3 & 4.6 \\
\hline No & 24.0 & 12.5 & 17.1 & 15.5 & 22.9 & 6.6 \\
\hline \multicolumn{7}{|l|}{ Cat in childhood } \\
\hline Yes & $26.1^{*}$ & 13.1 & $18.3^{*}$ & $17.6^{* *}$ & 24.3 & 6.3 \\
\hline No & 22.2 & 12.0 & 15.1 & 12.7 & 21.9 & 6.1 \\
\hline \multicolumn{7}{|l|}{ Dog in adulthood } \\
\hline Yes & 26.6 & 13.3 & 17.2 & $18.9^{*}$ & 25.7 & 5.6 \\
\hline No & 23.9 & 12.5 & 16.8 & 14.7 & 22.7 & 6.3 \\
\hline \multicolumn{7}{|l|}{ Dog in childhood } \\
\hline Yes & $27.1^{*}$ & $14.4^{*}$ & $19.2^{*}$ & 16.1 & 24.8 & 5.2 \\
\hline No & 22.6 & 11.6 & 15.4 & 14.8 & 22.2 & 6.8 \\
\hline Total & 24.3 & 12.6 & 16.8 & 15.3 & 23.2 & 6.2 \\
\hline
\end{tabular}


Table 3 Adjusted* odds ratios (OR) with 95\% confidence interval (CI) for the respiratory symptoms and asthma

\begin{tabular}{|c|c|c|c|c|c|c|c|c|c|c|c|c|}
\hline & \multicolumn{2}{|c|}{ Cough with phlegm } & \multicolumn{2}{|c|}{ Chronic cough } & \multicolumn{2}{|c|}{$\begin{array}{l}\text { Dyspnoea } \\
\text { grade } 2\end{array}$} & \multicolumn{2}{|c|}{ Attacks of dyspnoea } & \multicolumn{2}{|c|}{ Wheezing } & \multicolumn{2}{|c|}{ Asthma } \\
\hline & $\overline{\text { OR }}$ & $95 \% \mathrm{Cl}$ & $\overline{\text { OR }}$ & $95 \% \mathrm{Cl}$ & $\overline{O R}$ & $95 \% \mathrm{Cl}$ & $\overline{O R}$ & $95 \% \mathrm{Cl}$ & $\overline{O R}$ & $95 \% \mathrm{Cl}$ & $\overline{\text { OR }}$ & $95 \% \mathrm{Cl}$ \\
\hline \multicolumn{13}{|l|}{ Mould $†$} \\
\hline \multicolumn{13}{|l|}{ Never } \\
\hline Only earlier & 1.6 & (1.01 to 2.38 ) & 1.2 & (0.71 to 2.19$)$ & 1.5 & (0.92 to 2.47 ) & 1.7 & (1.06 to 2.72$)$ & 1.5 & (0.99 to 2.34 ) & 1.4 & (0.68 to 2.85$)$ \\
\hline Earlier and last year & 1.7 & (1.08 to 2.64 ) & 2.0 & (1.17 to 2.48$)$ & 2.3 & (1.35 to 3.85 ) & 1.5 & (0.91 to 2 to 59 ) & 2.3 & (1.46 to 3.47$)$ & 1.5 & (0.69 to 3.47 ) \\
\hline \multicolumn{13}{|l|}{ Water damage $\dagger$} \\
\hline \multicolumn{13}{|l|}{ Never } \\
\hline Only earlier & 1.2 & (0.84 to 1.72 ) & 1.2 & $(0.74$ to 1.86$)$ & 1.4 & (0.91 to 2.10$)$ & 1.1 & (0.74 to 1.74$)$ & 1.3 & (0.92 to 1.86$)$ & 1.4 & (0.78 to 2.62$)$ \\
\hline Earlier and last year & 1.2 & (0.74 to 2.01 ) & 1.2 & (0.61 to 2.19 ) & 1.2 & (0.63 to 2.15$)$ & 1.2 & (0.65 to 2.07 ) & 1.0 & (0.61 to 1.69 ) & 1.2 & (0.49 to 2.85$)$ \\
\hline \multicolumn{13}{|l|}{ Fitted carpets in bedroom } \\
\hline Yes & 0.7 & $(0.55$ to 0.85$)$ & 0.7 & $(0.53$ to 0.93$)$ & 0.9 & (0 to 71 to 1.94 ) & 0.7 & $(0.56$ to 0.94$)$ & 0.9 & $(0.69$ to 1.06$)$ & 0.9 & 0.62 to 1.32 ) \\
\hline \multicolumn{13}{|l|}{ No } \\
\hline \multicolumn{13}{|c|}{ Fitted carpets in living room } \\
\hline Yes & 1.0 & (0.73 to 1.32 ) & 1.1 & (0.75 to 1.58$)$ & 1.3 & (0.94 to 1.78 ) & 0.9 & (0.63 to 1.27$)$ & 0.9 & $(0.64$ to 1.16$)$ & 0.6 & $(0.36$ to 1.10$)$ \\
\hline No & & & & & & & & & & & & \\
\hline \multicolumn{13}{|l|}{ Cat in adulthood } \\
\hline Yes & 1.1 & (0.82 to 1.37 ) & 1.1 & $(0.78$ to 1.50$)$ & 1.2 & (0.88 to 1.63 ) & 0.9 & (0.65 to 1.20$)$ & 1.0 & (0.77 to 1.28 ) & 0.8 & (0.46 to 1.24 ) \\
\hline \multicolumn{13}{|l|}{ No } \\
\hline \multicolumn{13}{|l|}{ Cat in childhood } \\
\hline Yes & 1.2 & (0.99 to 1.51$)$ & 1.0 & (0.76 to 1.32 ) & 1.0 & (0.80 to 1.33 ) & 1.4 & (1.11 to 1.83 ) & 1.1 & (0.87 to 1.33 ) & 1.2 & (0.81 to 1.69 ) \\
\hline \multicolumn{13}{|c|}{ 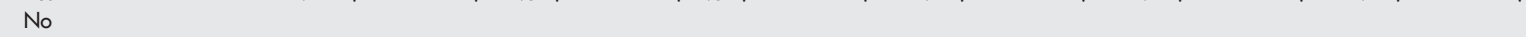 } \\
\hline \multicolumn{13}{|l|}{ Dog in adulthood } \\
\hline Yes & 1.1 & (0.81 to 1.44 ) & 1.0 & (0.67 to 1.42 ) & 1.2 & (0.84 to 1.68 ) & 1.4 & (1.01 to 1.93 ) & 1.0 & (0.78 to 1.38 ) & 0.9 & (0.55 to 1.61$)$ \\
\hline No & & & & & & & & & & & & \\
\hline \multicolumn{13}{|l|}{ Dog in childhood } \\
\hline Yes & 1.1 & (0.90 to 1.37 ) & 1.2 & (0.93 to 1.61$)$ & 1.3 & (1.0 to 1.65 ) & 0.9 & (0.72 to 1.19 ) & 1.0 & (0.82 to 1.25$)$ & 0.8 & (0.52 to 1.13 ) \\
\hline No & & & & & & & & & & & & \\
\hline
\end{tabular}

*Adjusted for sex, age, smoking status, educational level, pack years, and exposure to occupational dust or fumes.

†Odds ratios for mould and water damage are calculated without water damage and mould in the model, respectively. For all the other exposures, all the exposure variables are kept in the model as well as mould and water damage.

moving from houses with a poor indoor climate. This would tend to underestimate an exposure-disease relationship.

The frequency of self-reporting indoor exposures in our subjects younger than 44 years of age was approximately of the same magnitude as previously reported from the Nordic countries. ${ }^{67102526}$ To our knowledge, the present study is the first to present community based data on the distribution of these exposures in the elderly. For all the indoor exposures, even those describing lifetime events, the prevalence fell with increasing age. This is probably due to a tendency of older people to forget previous exposures. Another explanation could be that younger people know more about the potential hazards of moulds and/or are more willing to report them than elderly people. The age trend in frequency of reported moulds persisted after adjusting for the number of years lived in the dwelling.

We assessed a wider range of symptoms in this study than in previous studies. For all the symptoms examined, reporting of visible moulds was a risk factor, whereas exposure to cats or dogs in childhood gave a mixed picture. Having fitted carpets in the bedrooms was associated with a decrease in risk. These results could reflect the relative ease with which subjects can withdraw from the exposures; presumably it is easier to throw out carpets than to dispose of one's pets or to eradicate moulds. If so, then the effect of having carpets would be underestimated more than either the effect of pets or moulds.

Self-reported water damage was not associated with any of the respiratory symptoms or asthma. This finding has also been reported in several other studies. ${ }^{10112627}$ Water damage in itself is unlikely to be a causal factor for asthma or respiratory symptoms, but is a known risk factor for mould growth. This finding could therefore be the result of a mingling of subjects with some risk (water damage and mould growth) with subjects with no risk (only water damage, no moulds). The clinical point in this would be that only subjects who actually report moulds should be considered at significant risk.

The finding that mould exposure was associated with a higher risk of respiratory symptoms is in line with the results of other studies, ${ }^{6-11} 26$ of which only two adjusted for socioeconomic status. ${ }^{6}{ }^{8}$ Our findings persisted even after taking socioeconomic status as well as occupational airborne exposure into account.

Residual confounding by smoking was a concern, particularly with symptoms such as cough with phlegm and chronic

Table 4 Adjusted* attributable fraction (AF)† of four indoor exposure variables and smoking for five respiratory symptoms

\begin{tabular}{|c|c|c|c|c|c|c|c|c|}
\hline \multirow[b]{2}{*}{ Respiratory symptoms } & \multicolumn{2}{|l|}{ Moulds } & \multicolumn{2}{|c|}{ Cat in childhood } & \multicolumn{2}{|c|}{ Dog in childhood } & \multicolumn{2}{|c|}{ Smoking } \\
\hline & AF (\%) & $95 \% \mathrm{Cl}$ & AF (\%) & $95 \% \mathrm{Cl}$ & AF (\%) & $95 \% \mathrm{Cl}$ & AF (\%) & $95 \% \mathrm{Cl}$ \\
\hline Cough with phlegm & 3.4 & 1.0 to 5.9 & 7.6 & -0.7 to 15.1 & 2.9 & -3.2 to 8.6 & 21.9 & 12.7 to 30.2 \\
\hline Chronic cough & 3.9 & 0.0 to 7.6 & 0.3 & -12.9 to 11.9 & 6.6 & -3.0 to 15.2 & 19.1 & 4.9 to 31.3 \\
\hline Dyspnoea grade 2 & 4.5 & 1.3 to 7.5 & 1.7 & -9.5 to 11.7 & 7.4 & -0.3 to 14.5 & 1.9 & -9.8 to 12.3 \\
\hline Attacks of dyspnoea & 4.1 & 0.6 to 7.5 & 15.3 & 4.2 to 25.1 & - & - & 19.8 & 7.5 to 30.5 \\
\hline Wheezing & 4.7 & 2.0 to 7.2 & 3.1 & -5.2 to 10.8 & 0.3 & -5.9 to 6.2 & 30.1 & 20.8 to 38.3 \\
\hline
\end{tabular}

${ }^{*}$ All models were adjusted for age, sex, educational level, smoking habits, pack years, occupational airborne exposure, and all the other exposure variables. For moulds the model was not adjusted for water damage.

†Also referred to as "population attributable risk" (PAR). 
cough. Adjustment for smoking was therefore made, both in terms of smoking habits (current, ex, and never smoking) and pack years smoked. Furthermore, conducting the analyses among only never smokers produced the same trends in the estimated effects, but with a widening of the confidence intervals to the point of non-significance.

Exposure to visible moulds, having fitted carpets, or pets can be thought of as markers of allergens-namely, moulds, dust mites, and feline proteins. Having visible moulds in the house is almost certain to mean an increased exposure to mould spores which could trigger an allergic response from the airways. However, visible moulds could also be a sign of increased dampness which may cause increased levels of airborne bacteria, dust mites, and other microbial volatile organic compounds (MVOCs) in the dwelling. The major compounds of fungal cells are glucans, which have been shown to cause respiratory symptoms ${ }^{28}$ and bronchial hyperresponsiveness. ${ }^{1}$ Bjornsson et $a l^{29}$ found higher levels of airborne bacteria and house dust mite in houses of subjects with asthma symptoms. Some respiratory symptoms have also been found to be associated with higher levels of carbon dioxide, formaldehyde, and total concentrations of MVOCs in the indoor air. ${ }^{30}$ The mechanisms are not clear at present, and possibly differ between the different exposures.

A wide range of studies on pet keeping in childhood has not been able to ascertain whether or not pet keeping increases the risk for disease. ${ }^{31-34}$ Indeed, several studies have suggested a protective effect of pet ownership on allergic disease. $^{34}{ }^{35}$ The results from the large European Community Respiratory Health Survey were recently presented by Svanes et al. ${ }^{34}$ Pooling results from several countries, having a dog in childhood or adulthood was associated with a marginal increase in risk for having wheeze with and without cold. Overall, cat ownership was not a risk factor for either wheeze or hay fever in childhood or in adulthood. ${ }^{34}$ Svanes et al used serum IgE levels as a marker of atopy. Interestingly, while cat ownership was associated with an increased risk of wheeze in atopic subjects, dog ownership was associated with an increased risk only in non-atopic subjects. ${ }^{34}$ If indeed there is an association between pet ownership and respiratory disease, the mechanism is likely to be different between dogs and cats. In the present study no protective effect of pet ownership was found. Subjects who reported having a cat in childhood had an increased risk for two of the five symptoms examined, symptoms not examined in the ECRHS. When stratifying the analyses by reported hay fever, we found no overt changes in the relationship between any of the exposures and the symptoms. There was no interaction between hay fever and the exposures on the symptoms. It is possible that recall bias in the elderly blurred a relationship between pet exposure in childhood and the symptoms. However, re-analyses of the data after excluding subjects above 45 years of age did not alter the magnitude of the associations. Finally, we had no data on duration and degree of exposure, nor at what time during childhood the pet was kept. A better exposure characterisation is likely to improve the validity of the analyses. Exposure in early childhood may have a protective effect for asthma, while later exposure in childhood may have an opposite effect. ${ }^{31} 34$

Our study found that having fitted carpets in bedrooms was associated with a lower risk of respiratory symptoms. This was also found by Zock et al. ${ }^{11}$ The most likely explanation is that symptomatic subjects had removed the carpets before they answered the questionnaire. ${ }^{36}$

The attributable fraction can be interpreted as the proportion of the symptom load that would theoretically be eliminated if the exposure in question had not occurred. To our knowledge, this is the first study to estimate the burden of symptoms in the general population due to indoor air pollutants. The estimates are strongly dependent on the prevalence of the exposures in the population. Only about $9 \%$ of the current study population reported exposure to moulds. Thus, if mould exposure is under-reported, the adjusted attributable fraction could be underestimated. It is also important to note that the effect of preventing one exposure in a situation where several exposures are involved will depend on the order in which the exposures are prevented. However, our results give some perspective of the relative importance of moulds compared with smoking.

In conclusion, this study has shown that exposure to moulds is an independent risk factor for several respiratory symptoms in a general population covering a wide age span. The current advice to eradicate moulds and fitted carpets when possible is probably sound, whereas firm advice on pet ownership cannot be deduced from this study or from the current literature.

\section{Authors' affiliations}

T Duelien Skorge, A Gulsvik, P S Bakke, Institute of Medicine, University of Bergen, Haukeland University Hospital, Bergen, Norway T Duelien Skorge, T M L Eagan, A Gulsvik, P S Bakke, Department of Thoracic Medicine, Haukeland University Hospital, Bergen, Norway G E Eide, Centre for Clinical Research, Haukeland University Hospital, Bergen and Section for Epidemiology and Medical Statistics, Department of Public Health and Primary Health Care, University of Bergen, Bergen, Norway

Competing interests: none declared

\section{APPENDIX 1 QUESTIONNAIRES USED IN STUDY}

The wording of the indoor factors related questions was:

- Has there ever been mould or mildew on any surface, other than food inside your home? (yes, no, do not know) If yes, they were also asked to respond to this question:

- Has there been mould or mildew on any surfaces inside your home in the last 12 months? (yes, no)

- Has there ever been any water damage to the building or its contents? (yes, no, do not know) If yes, they were also asked to respond to this question:

- Has there been any water damage in the last 12 months? (yes, no)

- Are there fitted carpets in the room most used at home during the day? (yes, no)

- Are there fitted carpets in your bedroom? (yes, no)

- When you were a child did you have a cat as a pet? (yes, no)

- When you were a child did you have a dog as a pet? (yes, no)

- Do you have a cat now? (yes, no)

- Do you have a dog now? (yes, no)

The wording of the respiratory symptoms related questions was as follows:

- Do you have phlegm when coughing? (yes, no)

- Do you have a cough for 3 months or more altogether during a year? (yes, no)

- Are you breathless when you climb two flights of stairs at an ordinary pace? (yes, no)

- Do you ever have attacks of breathlessness? (yes, no)

- Have you ever had wheezing in your chest for the last 12 months? (yes, no)

- Have you ever been treated by a doctor or been hospitalised for asthma?

- (yes, no, do not know) 


\section{REFERENCES}

1 Brunekreef B, ed. Indoor environment. In: Respiratory epidemiology in Europe. Eur Respir Monograph 2000;15:384-99.

2 Brunekreef B. Associations between questionnaire reports of home dampnes and childhood respiratory symptoms. Sci Total Environ 1992;127:79-89.

3 Nafstad P, Oie L, Mehl R, et al. Residential dampness problems and symptoms and signs of bronchial obstruction in young Norwegian children. Am J Respir Crit Care Med 1998;157:410-4.

4 Strachan DP, Sanders CH. Damp housing and childhood asthma; respiratory effects of indoor air temperature and relative humidity. J Epidemiol Community Health 1989:43:7-14.

5 Strachan DP, Flannigan B, McCabe EM, et al. Quantification of airborne moulds in the homes of children with and without wheeze. Thorax 1990;45:382-7

6 Pirhonen I, Nevalainen A, Husman T, et al. Home dampness, moulds and their influence on respiratory infections and symptoms in adults in Finland. Eur Respir J 1996;9:2618-22.

7 Engvall K, Norrby C, Norback D. Asthma symptoms in relation to building dampness and odour in older multifamily houses in Stockholm. Int J Tuberc Lung Dis 2001;5:468-77.

8 Dales RE, Burnett R, Zwanenburg $\mathrm{H}$. Adverse health effects among adults exposed to home dampness and molds. Am Rev Respir Dis 1991;143:505-9.

9 Brunekreef B. Damp housing and adult respiratory symptoms. Allergy 1992;47:498-502.

10 Gunnbjornsdottir MI, Norback D, Plaschke $\mathrm{P}$, et al. The relationship between indicators of building dampness and respiratory health in young Swedish adults. Respir Med 2003;97:302-7.

11 Zock JP, Jarvis D, Luczynska C, et al. Housing characteristics, reported mold exposure, and asthma in the European Community Respiratory Health Survey. J Allergy Clin Immunol 2002;1 10:285-92.

12 Ng Man Kwong G, Das C, Proctor AR, et al. Diagnostic and treatment behaviour in children with chronic respiratory symptoms: relationship with socioeconomic factors. Thorax 2002;57:701-4.

$13 \mathbf{O}^{\prime}$ Shea E. Social gradients in years of potential life lost in Ireland. Eur J Public Health 2003:13:327-33.

14 Eagan T, Gulsvik A, Eide GE, et al. The effect of educational level on the incidence of asthma and respiratory symptoms. Respir Med 2004;98:730-6.

15 Bakke P, Gulsvik A, Lilleng $P$, et al. Postal survey on airborne occupational exposure and respiratory disorders in Norway: causes and consequences of non-response. J Epidemiol Community Health 1990:44:316-20.

16 Eagan TM, Bakke PS, Eide GE, et al. Incidence of asthma and respiratory symptoms by sex, age and smoking in a community study. Eur Respir J 2002;19:599-605.

17 Burney PG, Luczynska C, Chinn S, et al. The European Community Respiratory Health Survey. Eur Respir J 1994:7:954-60.

18 Gulsvik A, Bakke PS, Humerfelt S, et al. Measurements of respiratory symptoms and sample size to detect a given difference between treatmen groups in obstructive lung disease. Eur Respir Rev 1991;1:436-43.
19 Brogger JC, Bakke PS, Gulsvik A. Comparison of respiratory symptoms questionnaires. Int J Tuberc Lung Dis 2000;4:83-90.

20 Eagan TM, Gulsvik A, Eide GE, et al. Occupational airborne exposure and the incidence of respiratory symptoms and asthma. Am J Respir Crit Care Med 2002; 166:933-8.

21 Lemeshow DWHS. Applied logistic regression, 2nd edn. New York: John Wiley \& Sons, 2000:100-3

22 Royston P, Ambler G, Sauerbrei W. The use of fractional polynomials to model continuous risk variables in epidemiology. Int J Epidemiol 1999;28:964-74

23 Eagan TM, Eide GE, Gulsvik A, et al. Nonresponse in a community cohort study: predictors and consequences for exposure-disease associations. J Clin Epidemiol 2002:55:775-81.

24 Williamson IJ, Martin CJ, McGill G, et al. Damp housing and asthma: a casecontrol study. Thorax 1997;52:229-34.

25 Norback D, Biornsson E, Janson C, et al. Current asthma and biochemical signs of inflammation in relation to building dampness in dwellings. Int J Tuberc Lung Dis 1999;3:368-76.

26 Thorn J, Brisman J, Toren K. Adult-onset asthma is associated with selfreported mold or environmental tobacco smoke exposures in the home. Allergy 2001;56:287-92.

27 Jaakkola MS, Nordman H, Piipari R, et al. Indoor dampness and molds and development of adult-onset asthma: a population-based incident case-control study. Environ Health Perspect 2002;110:543-7.

28 Thorn J, Rylander R. Airways inflammation and glucan in a rowhouse area. Am J Respir Crit Care Med 1998;157:1798-803.

29 Bjornsson E, Norback D, Janson C, et al. Asthmatic symptoms and indoor levels of micro-organisms and house dust mites. Clin Exp Allergy 1995;25:423-31

30 Norback D, Bjornsson E, Janson C, et al. Asthmatic symptoms and volatile organic compounds, formaldehyde, and carbon dioxide in dwellings. Occup Environ Med 1995:52:388-95

31 Apelberg BJ, Aoki Y, Jaakkola JJ. Systematic review: Exposure to pets and risk of asthma and asthma-like symptoms. J Allergy Clin Immunol $2001 ; 107: 455-60$

32 Nafstad P, Magnus P, Gaarder PI, et al. Exposure to pets and atopy-related diseases in the first 4 years of life. Allergy 2001;56:307-12.

33 Hesselmar B, Aberg N, Aberg B, et al. Does early exposure to cat or dog protect against later allergy development? Clin Exp Allergy 1999;29:611-7.

34 Svanes C, Heinrich J, Jarvis D, et al. Pet-keeping in childhood and adult asthma and hay fever: European community respiratory health survey. J Allergy Clin Immunol 2003;1 12:289-300

35 Noertiojo K, Dimich-Ward H, Obata H, et al. Exposure and sensitization to cat dander: asthma and asthma-like symptoms among adults. J Allergy Clin Immunol 1999;103:60-5.

36 Verhoeff AP, Burge HA. Health risk assessment of fungi in home environments. Ann Allergy Asthma Immunol 1997:78:544-56.

\section{Scadding-Morriston Davies Joint Fellowship in Respiratory Medicine 2006}

This fellowship is available to support visits to medical centres in the UK or abroad for the purpose of undertaking studies related to respiratory medicine. Applications are invited from medical graduates practising in the UK, including consultants and irrespective of the number of years in that grade. There is no application form but a curriculum vitae should be submitted together with a detailed account of the duration and nature of the work and the centres to be visited, confirming that these have agreed to provide the facilities required. Please state the sum of money needed for travel and subsistence. A sum of up to $£ 20,000$ can be awarded to the successful candidate, or the sum may be divided to support two or more applications. Applications should be sent to the Secretary by 31 January 2006 at the following address, $\mathrm{Dr}$ I A Campbell, Secretary to the Scadding-Morriston Davies Fellowship, Llandough Hospital, Penarth, Vale of Glamorgan CF64 2XX. 